\title{
Catabolite Repressive Effects of 5-Thio-D-glucose on Saccharomyces cerevisiae
}

\author{
By VALGARDUR EGILSSON,* VILMUNDUR GUDNASON, \\ ADALBJÖRG JÓNASDOTTIR, SIGURDUR INGVARSSON AND \\ VALGERDUR ANDRESDOTTIR \\ University Hospital of Iceland, Department of Pathology, Laboratory of Cell Biology, \\ PO Box 1465, 121 Reykjavik, Iceland
}

(Received 27 May 1986)

\begin{abstract}
The effect of the glucose analogue 5-thio-D-glucose (5TG) on the yeast Saccharomyces cerevisiae was studied. Derepression of mitochondrial respiratory chain cytochromes, alcohol dehydrogenase (isoenzyme II), NADH dehydrogenase and maltase was inhibited by 0.5-2 mM-5TG. Growth rate was only slightly affected. Ethanol was efficiently produced with 2 mM-5TG in medium initially containing $0.25 \%$ glucose. Mutants resistant to the growth inhibitory effects of $5 \mathrm{TG}$ on glycerol medium showed resistance to the catabolite repressing effects of glucose. Other mutants, known to be catabolite repression resistant, showed resistance to 5TG. The analogue seems to inhibit derepression of glucose repressible enzymes with greater potency than glucose itself.
\end{abstract}

\section{INTRODUCTION}

Catabolite repression is a physiological condition seen in many unicellular organisms. When, for example, yeast cells are grown in medium containing glucose, fructose or mannose, enzymes of the Krebs cycle, the respiratory chain, the gluconeogenesis pathway and the glyoxylate shunt are repressed (for a review see Barnett, 1976). How catabolite repression is mediated in yeast is still enigmatic although the isoenzyme PII of hexokinase is clearly involved (Entian \& Frölich, 1984). In Escherichia coli, catabolite repression is mediated by cAMP whereas in yeast such a role has not been unequivocally demonstrated for that compound (Uno et al., 1984). The glucose analogue 2-deoxy-D-glucose (2DG) has proved useful for the isolation of catabolite repression resistant mutants (Zimmermann \& Scheel, 1977). It interferes with catabolite repression (Witt $e t$ al., 1966) but is very toxic to cells (van Wijk et al., 1969). Another glucose analogue, Dglucosamine, is a gratuitous glucose repressor (Witt et al., 1966). It is not metabolized and is nontoxic but is effective only at relatively high concentrations (Furst \& Michels, 1977). In this report we describe repressive effects of the glucose analogue 5-thio-D-glucose (5TG), which is shown to be less toxic than 2DG and effective at lower concentrations than D-glucosamine.

\section{METHODS}

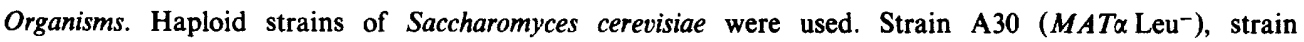
D11 $\left(M A T \mathrm{a} \mathrm{Ura}^{-} \mathrm{Trp}^{-}\right)$and strain BB $\left(M A T \alpha \mathrm{His}^{-} \mathrm{Trp}^{-}\right)$were from David Wilkie, Department of Microbiology, University College, London, UK. Strain cat 2.3-2A/18 (MATa his4 MAL2-8c MAL3 SUC3 hexl) was from K.-D. Entian, Physiologisch-Chemisches Institut, Universität Tübingen, FRG.

Isolation of mutants. Petite mutants, from strains A30 and D11, were isolated as described earlier (Egilsson et al., 1979). Mutants resistant to 5TG were obtained by exposing cells to $4 \mathrm{mM}-5 \mathrm{TG}$ on glycerol agar at cell densities of $10^{8}$ cells per plate and picking growing colonies. These were tested for resistance to repression by high concentrations of glucose; two mutants were selected for further experiments, one from strain D11, designated V106, and one from strain A30, designated VE1.

Abbreviations: 5TG, 5-thio-D-glucose; 2DG, 2-deoxy-D-glucose; ADH, alcohol dehydrogenase. 
Growth conditions. The medium contained $1 \%$ yeast extract (Difco) and carbon source as specified. Where solid medium was required, $1.5 \%(\mathrm{w} / \mathrm{v})$ agar (Difco) was used. For liquid culture, cells were grown in $100 \mathrm{ml}$ medium in $500 \mathrm{ml}$ flasks in a gyratory water bath at 150 r.p.m. and $30^{\circ} \mathrm{C}$. Cells grown in high glucose (initial concentration $6 \%$, w/v) were harvested in the exponential phase, i.e. in a catabolite repressed state (after about $12 \mathrm{~h}$ ). Cells grown in low glucose (initial concentration $0.25 \%$ ) were harvested in the stationary phase (after about $20 \mathrm{~h}$ ) to provide derepressed cells.

Growth rate, glucose and ethanol measurements. Growth rate in liquid medium was determined by measuring optical density at $610 \mathrm{~nm}$. Samples were taken aseptically, the cells pelleted and the supernatant used for glucose measurements (Trinder, 1969) and ethanol measurements (Skaftason \& Johannesson, 1975).

Cytochrome absorption spectra. Absolute cytochrome spectra of whole cells were measured with a double beam spectrophotometer, as described by Egilsson et al. (1979).

Growth inhibition test on solid media. The glucose analogues 5TG, D-glucosamine and 2DG were filter-sterilized (Millex $0.22 \mu \mathrm{m}$ ) into the medium at $50^{\circ} \mathrm{C}$. The medium contained as the only carbon source either glucose, galactose, maltose, raffinose, methyl $\alpha$-D-glucoside (each $2 \%, w / v)$ or glycerol $(4 \%, w / v)$. Growth inhibition was tested using a multiple inoculation device (Hughes \& Wilkie, 1970). To exclude possible cross-feeding, each strain was also plated one per plate.

Disruption of cells, enzyme activity measurements and starch gel electrophoresis. Cells were harvested by centrifuging at $1000 \mathrm{~g}$ for $5 \mathrm{~min}$. The pellet was washed twice in $0.1 \mathrm{~mm}$-potassium phosphate buffer, pH 6.4. Cells were disrupted with glass beads in a laboratory mixer (Ciriacy, 1975) and centrifuged at $2000 \mathrm{~g}$ for $10 \mathrm{~min}$. The supernatant was diluted in the same buffer to $20 \mathrm{mg} \mathrm{ml}^{-1}$ and used for enzyme activity measurements and starch gel electrophoresis. Protein was measured by the method of Bradford (1976). Enzyme activity measurements of maltase (EC 3.2.1.20), and NADH dehydrogenase (EC 1.6.99.3) were done as described by Zimmermann $e t$ al. (1977). Electrophoresis of alcohol dehydrogenase (ADH) was done as described by Ciriacy (1975). Electrophoresis of hexokinase was done in a Tris/maleate buffer system at $\mathrm{pH} 7.4$ and enzyme activity detected by the tetrazolium dye technique (Gudnason et al., 1984).

Surface appearance of colonies. Normally, colonies of strain BB grown from single cells on glycerol agar have a rough surface whereas those grown on glucose are smooth. Cells were grown on glycerol agar in the presence of 5TG (0.1 mM), and the surface appearance of colonies was examined after $5 \mathrm{~d}$.

Chemicals. Reagents for protein assay were from Bio-Rad. All other reagents, chemicals and nutrients were from Sigma.

\section{RESULTS AND DISCUSSION}

\section{Effect of $5 T G$ on growth}

5TG (2 mM) had no effect on the growth rate of strain D11 in liquid glucose medium, while with strain A30 the generation time was slightly longer (Table 1). Strains A30 and D11 were also grown on agar plates containing different carbon sources, in the presence of increasing concentrations of 5TG (Table 2). For utilizing non-zymohexoses derepression of certain catabolite repressible enzymes is required, e.g. galactokinase, maltase, methyl- $\alpha$-D-glucosidase and invertase for the utilization of galactose, maltose, methyl $\alpha$-D-glucoside and raffinose, respectively (Matern \& Holzer, 1977; Gascon et al., 1968; Adams, 1972; Khan \& Greener, 1977; Zimmermann \& Eaton, 1974; van Wijk et al., 1969; Hackel \& Khan, 1978). 5TG (0.1-0.3 mM) inhibited growth of strains A30 and D11 on glycerol medium (a non-fermentable substrate, the utilization of which requires derepression of the mitochondrial respiratory system); slightly higher concentrations $(0.3-0.8 \mathrm{~mm})$ inhibited growth on the non-zymohexoses (with the exception of strain D11 on galactose). It is concluded that 5TG interferes with the derepression of enzymes needed for utilization of these carbon sources. This conclusion appears to agree with the more direct measurements of enzymes discussed later.

No effect of 5TG was seen on growth on solid glucose medium $(2 \%)$ with the highest concentration tested ( $30 \mathrm{~mm}-5 \mathrm{TG}$ ). For comparison, it should be noted that concentrations of $2 \mathrm{DG}$ around $5 \mathrm{mM}$ were lethal to strains A30 and D11 on glucose medium, indicating stronger toxicity of the latter analogue. D-Glucosamine exerted catabolite repressive effects on strains A30 and D11, but 3-4 times higher concentrations were required than of 5TG. The highest concentration of D-glucosamine tested $(30 \mathrm{mM})$ did not inhibit growth on glucose medium (details not shown). 
Table 1. Effects of $5 T G$ on generation time and maltase and NADH dehydrogenase activities of S. cerevisiae

Growth was measured by optical density and the generation time calculated. The figures are means of four measurements. The standard deviation was less than $10 \%$. Cells grown in low glucose (initial concentration $0.25 \%$ ) were harvested just as the glucose had been used up.

\begin{tabular}{|c|c|c|c|c|c|c|}
\hline \multirow[b]{3}{*}{ Strain } & \multicolumn{3}{|c|}{ Culture conditions } & \multirow{3}{*}{$\begin{array}{c}\text { Generation } \\
\text { time } \\
\text { (min) }\end{array}$} & \multicolumn{2}{|c|}{$\begin{array}{c}\text { Enzyme activity } \\
{\left[\mathrm{nmol} \min ^{-1}(\mathrm{mg} \text { protein })^{-1}\right]}\end{array}$} \\
\hline & \multicolumn{2}{|c|}{ Glucose $(\%, w / v)$} & \multirow[b]{2}{*}{ 5TG (mM) } & & \multirow[b]{2}{*}{ Maltase } & \multirow{2}{*}{$\begin{array}{c}\text { NADH } \\
\text { dehydrogenase }\end{array}$} \\
\hline & Initial & Final & & & & \\
\hline \multirow[t]{3}{*}{ A30 } & $6 \cdot 0$ & $4 \cdot 0$ & $0 \cdot 0$ & 88 & $1 \cdot 1$ & 0.60 \\
\hline & 0.25 & 0.0 & 0.0 & 110 & $14 \cdot 0$ & 1.97 \\
\hline & 0.25 & 0.0 & $2 \cdot 0$ & 130 & $4 \cdot 2$ & 0.96 \\
\hline \multirow[t]{3}{*}{ D11 } & 6.0 & 3.9 & 0.0 & 85 & 0.9 & 0.60 \\
\hline & 0.25 & 0.0 & 0.0 & 104 & $13 \cdot 4$ & 1.92 \\
\hline & 0.25 & 0.0 & $2 \cdot 0$ & 106 & 1.4 & 0.67 \\
\hline \multirow[t]{2}{*}{ VE1 } & $6 \cdot 0$ & $4 \cdot 2$ & 0.0 & 114 & $5 \cdot 5$ & ND \\
\hline & 0.25 & 0.0 & $2 \cdot 0$ & 120 & 8.7 & ND \\
\hline \multirow[t]{2}{*}{ V106 } & $6 \cdot 0$ & $4 \cdot 1$ & 0.0 & 112 & $8 \cdot 8$ & ND \\
\hline & 0.25 & 0.0 & $2 \cdot 0$ & 125 & $11 \cdot 2$ & ND \\
\hline
\end{tabular}

Table 2. Effect of $5 T G$ on growth of $S$. cerevisiae on various carbon sources

Figures shown are the lowest concentrations of 5TG completely inhibiting growth on agar plates as scored after 48 h. Carbon sources: Glc, glucose; Gol, glycerol; Gal, galactose; Mal, maltose; MDG, methyl $\alpha$-D-glucoside; Raf, raffinose. Cells were freshly grown overnight before plating. All experiments were performed at least three times and the results presented are means. Standard deviation was always less than $10 \%$ of the given figures.

\begin{tabular}{lcccccr}
\multicolumn{7}{c}{$\begin{array}{c}\text { Lowest concentration of 5TG (mM) } \\
\text { completely inhibiting growth on: }\end{array}$} \\
\cline { 2 - 7 } & Glc & Gol & Gal & Mal & MDG & Raf \\
A30 & $>30$ & 0.1 & 0.3 & 0.3 & 0.8 & 0.4 \\
D11 & $>30$ & 0.3 & $>6.1$ & 0.4 & 0.8 & 0.4 \\
VE1 & $>30$ & $>6.1$ & $>6.1$ & $>6.1$ & $>6.1$ & $>6.1$ \\
V106 & $>30$ & $>6.1$ & $>6.1$ & $>6.1$ & $>6.1$ & $>6.1$ \\
Cat 2.3-2A/18 & $>30$ & $>6.1$ & $>6.1$ & $>6.1$ & $>6.1$ & $>6.1$ \\
D11 petite' & $>30$ & $-*$ & ND & ND & ND & ND
\end{tabular}

* Strain D11 'petite' is incapable of growth on Gol.

ND, Not determined.

Effect of $5 T G$ on some catabolite repressible factors

Table 1 shows the activity of two catabolite repressible enzymes, maltase and NADH dehydrogenase, measured in cells grown in glucose medium with or without 5TG. 5TG (2 mM) in low glucose medium suppressed the activity of these two enzymes as compared with derepressed control cultures. By contrast, the mutant strains V106 and VE1, which were resistant to growth inhibition by $5 \mathrm{TG}$ on glycerol medium, showed high maltase activity with $4 \%$ glucose left in the medium.

Electrophoresis of ADH was carried out on the parent strains, A30 and D11. ADH isoenzyme II is normally glucose repressible (Ciriacy, 1975). In cultures where $4 \%$ glucose was left in the medium, this isoenzyme was absent; in derepressed control cultures (starting with $0.25 \%$ glucose) the band was present, but absent if 2 mM-5TG had been added. The non-glucose repressible ADH I was present in all cultures. Fig. 1 shows absolute absorption spectra for respiratory cytochromes. 5TG strongly inhibited the derepression of the cytochromes (trace C) in the parent strain, even at very low concentration ( $1 \mathrm{mM})$. Glucose itself, on the other hand, 


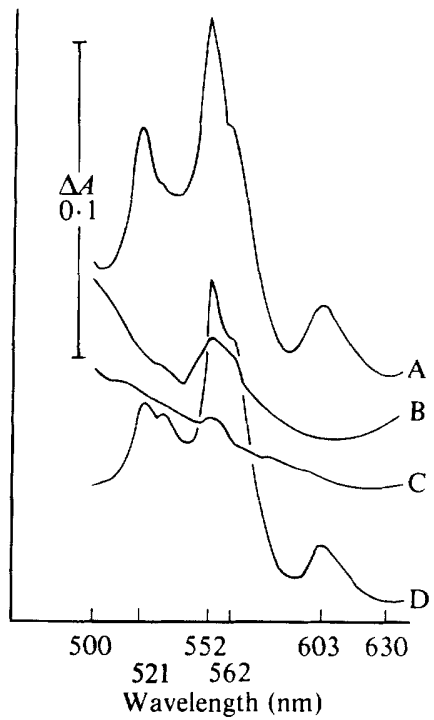

Fig. 1. Absorption spectra of whole yeast cells in the respiratory cytochrome absorbing region of $500-$ $630 \mathrm{~nm}$. The major absorption peaks for cytochromes $a a_{3}, b$ and $c$ are $603 \mathrm{~nm}, 562 \mathrm{~nm}$ and $552 \mathrm{~nm}$ respectively. Strain D11: A, in derepressing medium, with an initial glucose concentration of $0.25 \%$ and cells harvested at a glucose concentration of zero (number of experiments, $n=7$ ); $\mathrm{B}$, in repressing medium, with an initial glucose concentration of $6 \%$ and cells harvested at a glucose concentration of $4 \%(n=5) ; \mathrm{C}$, as in A plus $2 \mathrm{~mm}-5 \mathrm{TG}(n=5)$. Strain V106: D, in repressing medium, with an initial glucose concentration of $6 \%$ and cells harvested at a glucose concentration of $4 \%(n=4)$.

allowed derepression at 10-15 mM (data not shown). In the mutants, V106 and VEl, cytochromes were derepressed at a glucose concentration of $4 \%$. Only the spectra for D11 and its mutant V106 are shown; the set of spectra for A30 and its mutant, VE1, was very similar.

Strain BB was used to study the effects of $5 \mathrm{TG}$ on the surface appearance of colonies. With $0.1 \mathrm{mM}-5 \mathrm{TG}$ in glycerol agar, colonies showed a smooth surface as did colonies grown on glucose agar, while colonies on control glycerol plates had the rough appearance characteristic of this strain. The effect of 5TG seems to parallel the catabolite repressive effect on enzymes and growth described above.

The results presented so far show that proliferation occurs in cultures suppressed by $5 \mathrm{TG}$. The cells use glycolysis, as indicated by ethanol production (strains A30 and D11 giving an ethanol concentration of around $0.1 \%$ in stationary phase low glucose cultures with 2 mM-5TG).

\section{Mutants resistant to $5 T G$}

The mutants V106 and VE1 were strongly resistant to repression by high glucose concentration as regards cytochrome content and maltase activity (Fig. 1, Table 1), and showed strong resistance to 5TG on non-zymohexose medium (Table 2). The catabolite repression resistant mutant cat 2.3-2A/18 (Entian \& Fröhlich, 1984) showed strong resistance to 5TG on the non-zymohexoses and on glycerol medium (Table 2). Cytochromes were also derepressed in this strain in the presence of $2 \mathrm{~mm}-5 \mathrm{TG}$ in medium with an initial glucose concentration of $0.25 \%$. In other words, cross-resistance is seen between $5 \mathrm{TG}$ and D-glucose.

The analogues 2DG and D-glucosamine have been reported to cause catabolite repression in yeast (Witt et al., 1966; Furst \& Michels, 1977) and we observed the same effect on strains A30 and D11 using similar concentrations of the analogues. The mutants VE1 and V106 also showed resistance to both $2 \mathrm{DG}$ and $\mathrm{D}$-glucosamine. The strain cat $2.3-2 \mathrm{~A} / 18$, which is catabolite repression resistant, showed resistance to all three analogues (data not shown). This strain has a mutation in $H E X I$, the structural gene of hexokinase PII (Entian, 1980). Electrophoresis of hexokinase in VE1 and V106 showed both isoenzymes PI and PII to be present (results not shown). 
In summary, we have shown that at a concentration of 0.5-2 mM the glucose analogue 5-thioD-glucose allows the proliferation of yeast cells in low glucose medium but at the same time inhibits the derepression of a number of catabolite repressible enzymes. The mechanism of action may be similar to that of D-glucose itself although the analogue seems to be more potent. We hope the analogue will be useful in studies on the phenomenon of catabolite repression as it is less toxic than $2 \mathrm{DG}$ and effective at a lower concentration than D-glucosamine.

This work was supported by the Science Fund of Iceland, which is gratefully acknowledged.

\section{REFERENCES}

ADAMS, B. D. (1972). Induction of galactokinase in Saccharomyces cerevisiae: kinetics of induction and glucose effects. Journal of Bacteriology 111, 308-315.

BARNETT, J. A. (1976). The utilization of sugar by yeasts. Advances in Carbohydrate Chemistry and Biochemistry 32, 125-234.

BRADFORD, M. (1976). A rapid and sensitive method for the quantitation of microgram quantities of protein utilizing the principle of protein-dye binding. Analytical Biochemistry 72, 248-254.

CIRIACY, M. (1975). Genetics of alcohol dehydrogenase in Saccharomyces cerevisiae. I. Isolation and genetic analysis of adh mutants. Mutation Research 29, 315326.

Egilsson, V., Evans, I. H. \& Wilkie, D. (1979). Toxic and mutagenic effects of carcinogens on the mitochondria of Saccharomyces cerevisiae. Molecular and General Genetics 174, 39-46.

ENTIAN, K.-D. (1980). Genetic and biochemical evidence for hexokinase PII as a key enzyme involved in carbon catabolite repression in yeast. Molecular and General Genetics 178, 633-637.

ENTIAN, K.-D. \& Frölich, K.-U. (1984). Saccharomyces cerevisiae mutants provide evidence of hexokinase PII as a bifunctional enzyme with catabolite and regulatory domains for triggering carbon catabolite repression. Journal of Bacteriology 158, 29-35.

FURST, A. \& Michels, C. A. (1977). An evaluation of D-glucosamine as a gratuitous catabolite repressor of Saccharomyces carlsbergensis. Molecular and General Genetics 155, 309-314.

Gascon, S., Neuman, N. P. \& Lampen, J. O. (1968). Comparative study of the properties of the purified internal and external invertases from yeast. Journal of Biological Chemistry 243, 1573-1577.

GUDNASON, V., INGVARSSON, S., JONASDOTTIR, A., ANDRESDOTTIR, V. \& EgILSSON, V. (1984). Isoenzyme patterns and subcellular localization of hexokinases in human breast cancer and non-pathological breast tissue. International Journal of Cancer 34, 63-66.

HACKEL, R. A. \& KhaN, N. A. (1978). Genetic control of invertase formation in Saccharomyces cerevisiae. II. Isolation and characterization of mutants conferring invertase hyperproduction in strain EK-6B carrying the suc3 gene. Molecular and General Genetics 164, 295-302.
Hughes, A. R. \& Wilkie, D. (1970). Preferential inhibition of respiration in Saccharomyces cerevisiae: correlation with chlorpromazine. Biochemical Pharmacology 19, 2555-2560.

KhAN, N. A. \& Greener, A. (1977). Effects of petite mutation on maltose and alfa-methyl-glucoside fermentation. Molecular and General Genetics 150, $107-$ 108.

MATERN, H. \& Holzer, H. (1977). Catabolite inactivation of the galactose uptake mechanism in yeast. Journal of Biological Chemistry 252, 6399-6402.

Skaftason, J. \& Johannesson, Th. (1975). Akvardanir a alcoholi (ethanoli) i blodi. Timarit logfraedingafelagsins (Reykjavik) 25, 5-17.

TRINDER, P. (1969). Determination of blood glucose using an oxidase-peroxidase system with a noncarcinogenic chromogen. Clinical Pathology 22, 158161.

Uno, I., Matsumoto, K., Adachi, K. \& Ishikawa, T. (1984). Characterization of cyclic AMP requiring yeast mutants: alterations in the catalytic subunit of protein kinase. Journal of Biological Chemistry 259, 12508-12513.

VAN WIJK, R. J., OvwEhAND, H., VAN DEN Bos, T. \& KONINGSBERGER, V. V. (1969). Induction and catabolite repression of alpha-methyl-glucosidase synthesis in protoplasts of Saccharomyces cerevisiae. Biochimica et biophysica acta 186, 178-191.

WitT, I., KRONAU, R. \& Holzer, H. (1966). Repression von Alkoholdehydrogenase, Malatdehydrogenase, Isocitratlyase und Malatsynthase in Hefe durch Glucose. Biochimica et biophysica acta 118, 522537.

ZimmermanN, F. K. \& EAton, N. R. (1974). Genetics of induction and catabolite repression of maltase synthesis in Saccharomyces cerevisiae. Molecular and General Genetics 134, 261-272.

ZimmermanN, F. K. \& ScheEL, I. (1977). Mutants of Saccharomyces cerevisiae resistant to carbon catabolite repression. Molecular and General Genetics 154, $75-82$.

ZimmermanN, F. K., KAUfMANN, I,, RASENBERGER, H. \& HaussmanN, P. (1977). Genetics of carbon catabolite repression in Saccharomyces cerevisiae. Genes involved in the derepression process. Molecular and General Genetics 151, 95-103. 